\title{
Caffeine Associated with Exercise Actions on Glycemic Metabolism and Insulin Resistance in Diabetic Animals
}

\author{
Luiz Augusto da Silva ${ }^{1,4,}{ }^{*}$, Jéssica Wouk $^{2}$, Vinicius Muller Reis Weber ${ }^{3}$, Leandro Ricardo \\ Altimari $^{3}$, Antônio Carlos Dourado ${ }^{3}$, Carlos Ricardo Maneck Malfatti ${ }^{2}$ and Raul Osiecki ${ }^{4}$ \\ ${ }^{1}$ Guairacá College, Physical Education Collegiate, Guarapuava, Paraná, Brazil \\ ${ }^{2}$ Midwest State University of Paraná, Guarapuava, Paraná, Brazil \\ ${ }^{3}$ Londrina State University, Physical Education and Sport Center, Londrina, Paraná, Brazil \\ ${ }^{4}$ Post-Graduation of Physical Education, Federal university of Paraná, Curitiba, Paraná, Brazil
}

\begin{abstract}
Objective: evaluate glycemic metabolism and its relationship with insulin resistance in diabetic animals after caffeine consumption associated with exercise.

Material and Methods: 48 animals, of 60 days, divided in four groups: Control, Diabetic, Control+Exercise, Diabetes+Exercise, Caffeine, Diabetes+Caffeine, Exercise+Caffeine and Diabetes+Caffeine+Exercise. Diabetes model was induced by intraperitoneal administration of $120 \mathrm{mg} / \mathrm{kg}$ of alloxan. On the test day, $6 \mathrm{mg} / \mathrm{kg}$ of caffeine were administrated 30 minutes before exercise and the animals performed a 60 minutes' session of predominantly aerobic exercise, using an overload of $6 \%$ of their body's weight. With 90 days old, the animals were submitted to an oral glucose tolerance test (OGTT) to verify their glycemic curve. During thirty days of aerobic exercise and/or caffeine treatment, the animals had their glycemia evaluated. At the end of the period, the OGTT was re-evaluated. So, the animals were sacrificed for biochemical analysis (glucose, muscle glycogen and hepatic) and hormonal (insulin). The animals were trained during 30 days by swimming tank, with $4 \%$ of extra weight a 40 -minute session, daily.
\end{abstract}

Results: Caffeine treatment increased plasma insulin concentration compared to healthy controls $(95 \%, p<0.05)$. Insulin resistance also reduced for trained diabetic animals treated with caffeine compared to healthy animals (IRI, OGTT and HOMA-IR).

Conclusion: Caffeine and training with aerobic exercise in healthy and diabetic animals' improve biologic systems, increasing the physical ability of the body to resist situations seeking to adapt the tissues to better function.

Keywords: Metabolism, Insulin resistance, Glucose.

\section{INTRODUCTION}

The treatment of diabetes mellitus (DM) should be associated with lifestyle-modifying treatments, altering behaviors such as smoking, physical inactivity and poor eating habits [1], and using strategies to control rapidly or in the case of drug use.

Physical exercise [2] and diet [3] are the first means of treatment for people diagnosed with DM. The control of some modifiable risk factors such as weight, habitual food consumption, tobacco use and physical activity showed a potential to reduce the risk of developing DM in individuals with a family history (88\%) [4].

The glycemic control established by diet and physical exercise has important benefits in preventing hyperglycemia [2], frequently observed in diabetic patients, both before and after exercise. In addition, blood glucose control has a long-term positive impact

*Address correspondence to this author at the Faculdade Guairacá, Guarapuava-PR, 85040-080, Brazil; Tel: +55-42-3621-1000;

Fax: +55-42-3629-8165; E-mail: lasilva7@hotmail.com on the clinical profile of diabetic patients, delaying the process of tissue damage associated with this metabolic complication [5].

It is well accepted that physical exercise may be related to increased insulin sensitivity, Glut expression4 and glycogen synthase activity in muscle cells in DM, and this stimulus may remain for up to 48 hours [6]. Physical exercise induces important changes in glucose homeostasis, which can rapidly decrease blood levels in people with diabetes. Reduced blood glucose levels should be monitored during the planned activity $[7,8]$.

Some metabolic mechanisms have been shown after the administration of caffeine on DM. In the study by Guarino et al. [9], chronic consumption of caffeine (25 mg/kg) was shown to control glycemic and fatty acid levels and reversed age-induced insulin resistance in wistar rats. These effects were mediated by increased activity adenosine monophosphate kinase (AMPK) and glucose transporter type 4 (Glut4) translocation.

(C) 2018 SET Publisher 
Thus, it becomes relevant to deepen the knowledge about the possible effects of caffeine associated with physical exercise on glycemic and hormonal control, since the literature has demonstrated isolated benefits of these strategies in maintaining a healthy life. Thus, the objective of the present study was to evaluate glycemic metabolism and its relationship with insulin resistance in diabetic animals after caffeine consumption associated with exercise.

\section{MATERIAL AND METHODS}

\section{Animals}

Forty-eight male Wistar rats at 60 days of age were used in the study. The animals were kept in cages with controlled temperature $\left(23 \pm 2^{\circ} \mathrm{C}\right)$ and humidity $(55 \pm$ $10 \%$ humidity), and a light/dark cycle of $12 \mathrm{~h}$. This study was approved by the Ethics Committee of research studies using animals (015/2015 Protocol).

\section{Diabetes Induction and Experimental Design}

The animals were divided into 8 groups: (1) Control (weights of $393 \pm 44 \mathrm{~g}$ ), (2) Diabetes (weights of $308 \pm$ $40 \mathrm{~g}$ ), (3) Control+Exercise (weights of $398 \pm 30 \mathrm{~g}$ ); (4) Diabetes+Exercise (weights of $296 \pm 24 \mathrm{~g}$ ) (5) Caffeine (6 $\mathrm{mg} / \mathrm{kg}$ ) (weights of $395 \pm 32 \mathrm{~g}$ ); (6) Diabetes+Caffeine $(6 \mathrm{mg} / \mathrm{kg}$ ) (weights of $298 \pm 23 \mathrm{~g}$ ) (7) Exercise+ Caffeine $(6 \mathrm{mg} / \mathrm{kg}$ ) (weights of $392 \pm 28$ g) and, (8) Diabetes+Exercise+Caffeine (6 mg/kg) (weights of $300 \pm 19 \mathrm{~g}$ ). Alloxan (ALX) (Sigma, St. Louis, USA) dissolved in sodium chloride solution $(0,9 \%)$ was administered intraperitoneally (ip) (120 $\mathrm{mg} / \mathrm{kg}$ ), after $12 \mathrm{~h}$ of fasting. Rats with fasting BG values between 150 and $250 \mathrm{mg} / \mathrm{dL}$ were considered diabetic. With 90 days old, the animals were submitted to an oral glucose tolerance test (OGTT) to verify their glycemic curve. During thirty days of aerobic exercise and/or caffeine treatment, the animals had their glycemia evaluated. At the end of the period, the OGTT was re-evaluated. So, the animals were sacrificed for biochemical analysis (glucose, muscle glycogen and hepatic) and hormonal (insulin).

\section{Effort Exercise Test and Training}

All animals were adapted to an aquatic environment to be able to swim during the test, through one daily session of $10 \mathrm{~min}$, for seven days prior to the experiment, in a swimming tank with $40 \mathrm{~cm}$ in depth, 70 $\mathrm{cm}$ in diameter, and water heated to $30 \pm 1{ }^{\circ} \mathrm{C}$, according to the protocol proposed by Gobatto et al. [10] During 30 days, the animals training by swimming tank, with an extra weight equivalent to $4 \%$ extra weight a 40-minute session, according to the protocol modified proposed by Scariot et al. [11]. Exercise sessions and laboratory procedures were always conducted at the same time of the day (08:00 am). Daily, the caffeine groups received $6 \mathrm{mg} / \mathrm{kg}$ during 30 days, 30 minute before exercise.

\section{Oral Glucose Tolerance Test}

Blood was collected from the tail vein in animals that fasted for $12 \mathrm{~h}$ to a posterior glucose analysis. These animals subsequently received one single dose of glucose (1 $\mathrm{mg} / \mathrm{kg}$ of body weight) by gavage, and new blood samples were collected at times 30,60 , and $120 \mathrm{~min}$. Blood glucose levels were determined in a glucometer (Accu-chek Advantage ${ }^{\circledR}$ ).

\section{Hormonal and Biochemical Analyses}

Blood glucose doses were performed in a glucometer (ACCU-CHEK ${ }^{\circledR}$ Active $^{\circledR}$ ) using approxi-

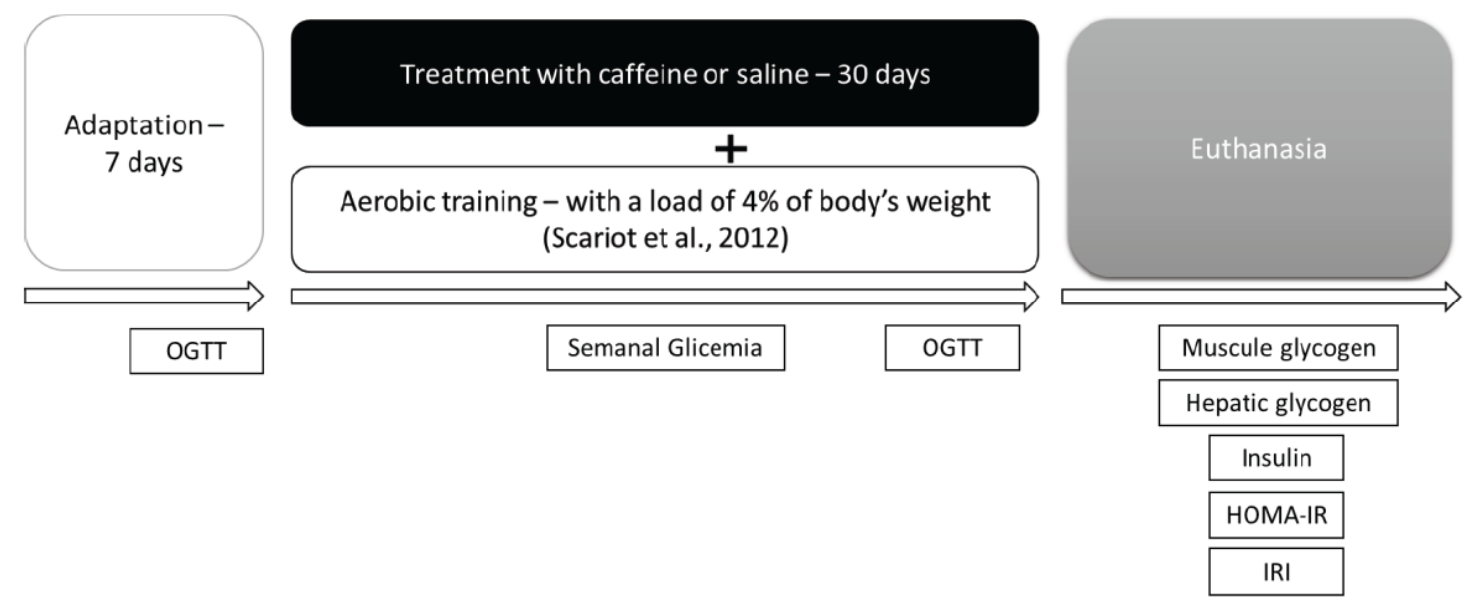

Figure 1: Experimental design. OGTT Oral glucose tolerance test; HOMA-IR: homeostatic model assessment - insulin resistance; IRI: Insulin resistance index. 
mately $25 \mu \mathrm{l}$ of blood collected through caudal puncture, before and after of the effort test. The insulin levels were determined by radioimmunoassay (RIA).

\section{Estimates of Insulin Sensitivity}

The insulin sensitivity was calculated in two ways:

HOMA-IR: insulin ( $\mu \mathrm{UI} / \mathrm{mL})$ / glucose $(\mathrm{mmol} / \mathrm{L}) \times 100$

Insulin resistance index $(\mathrm{IRI})$ : insulin $(\mu \mathrm{UI} / \mathrm{mL}) \mathrm{X}$ glucose $(\mathrm{mmol} / \mathrm{L})$

\section{Muscle and Hepatic Glycogen Analyses}

The hepatic and muscular tissue was weighed, homogenized in $4 \mathrm{ml}$ of trichloroacetic acid (TCA, 10\%) and centrifuged (2000 g / $\left.4{ }^{\circ} \mathrm{C} / 10 \mathrm{~min}\right)$. For glucose dosage from tissue glycogen, we used the Glucox commercial kit (Doles, Goiás, Brazil).

\section{Statistical Analyses}

All results are presented as mean \pm E.P.M. Statistical analysis was performed using a T Student test for unpaired sample or one-way MANOVA. Values were considered statistically significant based on $P<$ 0.05 . The post hoc Student-Newman-Keuls test was used, when appropriate, to identify differences between groups.

\section{RESULTS}

Figure 2 depicts weekly blood glucose during the 4 weeks of caffeine training and/or treatment. The weekly glycemia of the animals was significantly higher for the diabetic control groups with and without caffeine training and / or treatment compared to healthy control groups throughout the experiment $(388 \%, F(7.41)=$ 49.426; <0.001).

Figure 3 represents serum insulin in the different groups after training and / or treatment with caffeine. The values of insulin after caffeine treatment and / or training were higher for the control groups $(231 \%, \mathrm{~F}$ $(7.41)=9.993, p=0.001)$ compared to the diabetic groups. A significant increase in plasma concentrations in the caffeine group $(95 \%, F(7.41)=9.993, p=0.029)$ and in the Exercise + Caffeine group (56\%, $F(7.41)=$ 9,993, $p<0.004)$ compared to Control and Exercise groups.

Figure 4 depicts blood glucose during OGTT in the different groups before and after training and / or treatment with caffeine. Before training and $/$ or treatment with caffeine, diabetic animals had the highest glycemia compared to healthy animals throughout the analysis at their 30,60 and $120 \mathrm{~min}$ times. The glycemic curve was significantly higher for the diabetic groups compared to the values related to the control groups at 30 minutes $(175 \%, F(7.41)=$ 11.077, $\mathrm{P}<0.001)$ and 60 minutes $(150 \%, F 7.41)=$ 13142, $p<0.001)$. However, at 120 minutes the mice Diabetes + Exercise and the mice Diabetes + Exercise + Caffeine did not differ significantly with the control animals, both the animals trained and / or treated with caffeine $(66 \%, F(7.41)=6.626, P=0.138)$, whereas animals from the Diabetes and Diabetes+Caffeine

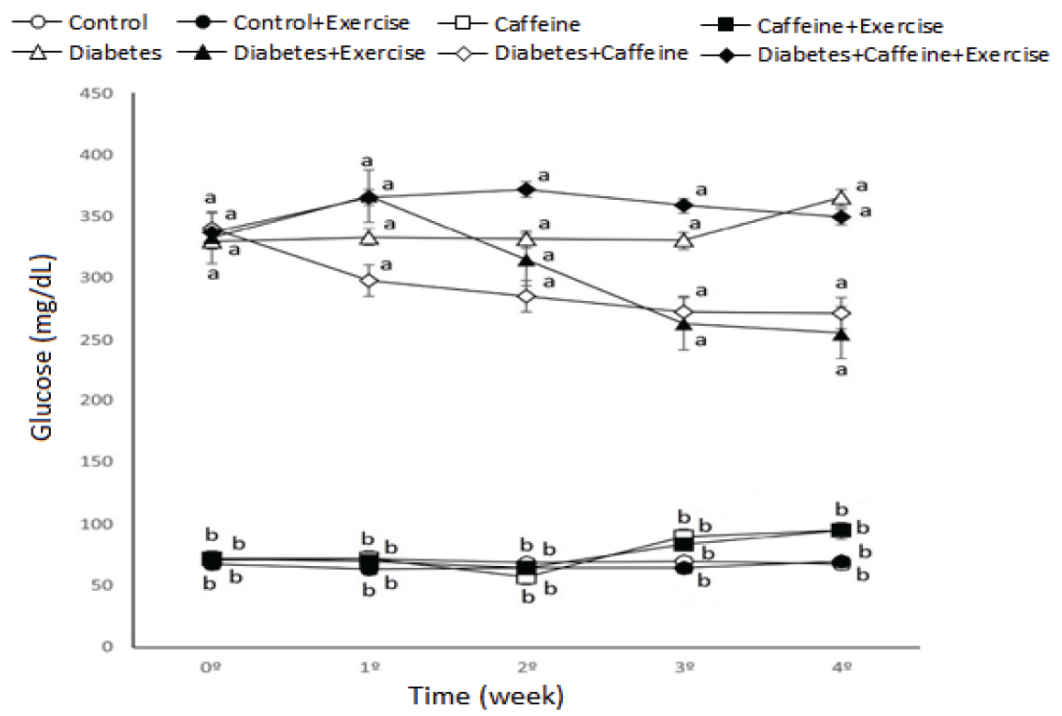

Figure 2: Weekly glycemia before and during caffeine training and/or treatment in control rats $(\circ)$, diabetic rats $(\Delta)$, control + exercise rats $(\bullet)$, diabetic rats + exercise $(\boldsymbol{\Delta})$, control + caffeine rats $(\square)$, diabetic rats + caffeine $(\diamond)$, control rats + exercise + caffeine $(\boldsymbol{\square})$ and diabetic rats + exercise + caffeine $(\bullet)$. The data are presented in mean $\pm S E M, n=6$, different letters $(a, b, c)=$ $\mathrm{P}<0.05$ (Tukey after one-way MANOVA). 

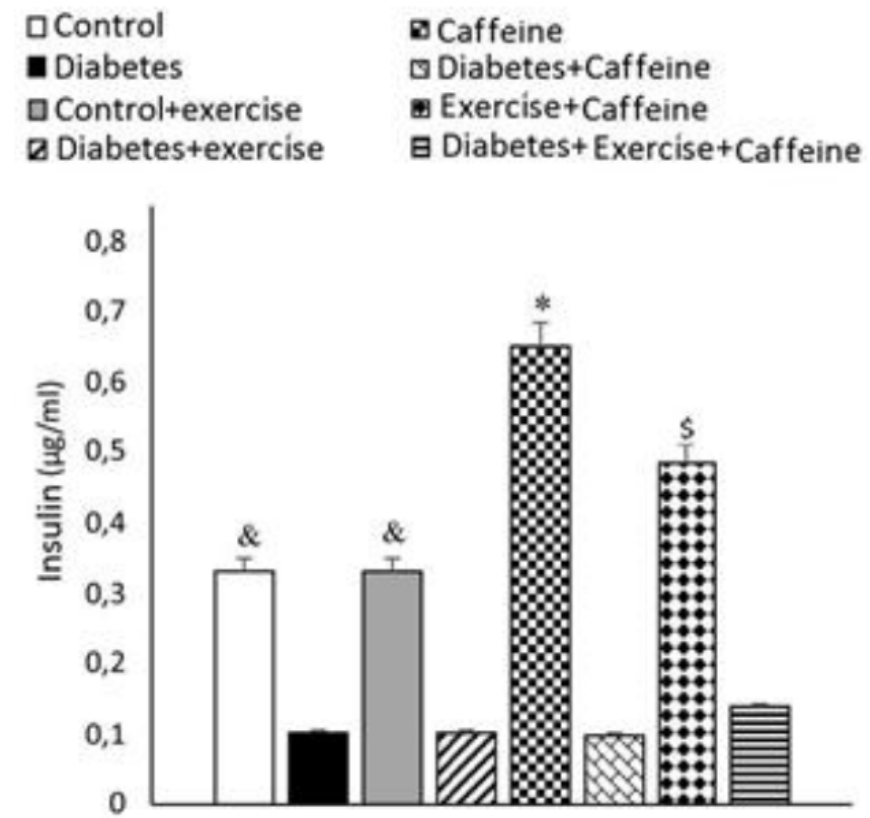

Figure 3: Plasma levels of insulin after training and/or treatment with caffeine. The data are presented in mean \pm SEM, $n=6,{ }^{*}$, $\$$ and $\&=P<0.05$ when compared to the other groups (Tukey after MANOVA).

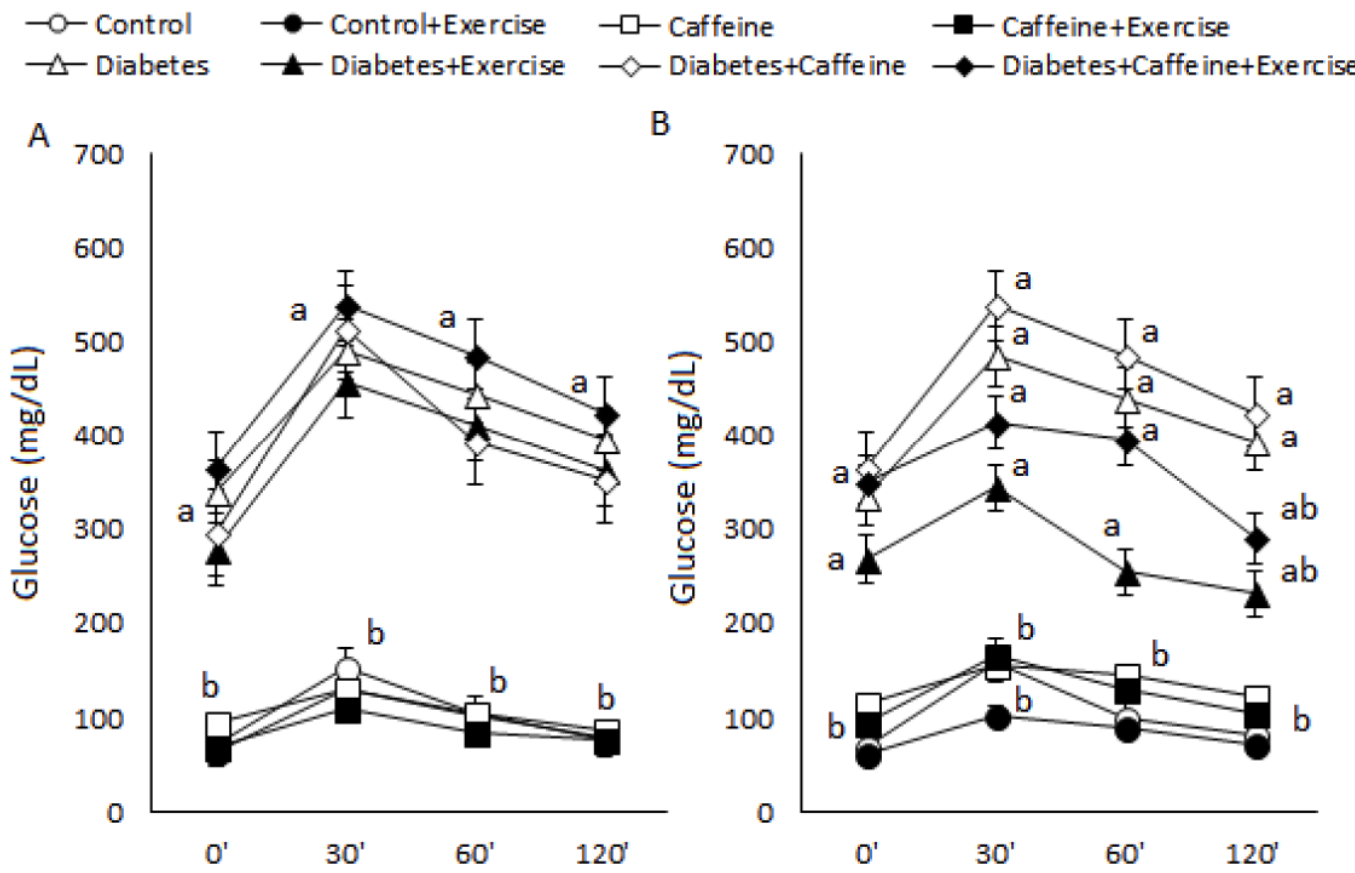

Figure 4: Oral glucose tolerance test $(\mathbf{A})$ before and $(\mathbf{B})$ after training and/or caffeine treatment in control rats $(\circ)$, diabetic rats $(\Delta)$, control + exercise rats $(\bullet)$, diabetic rats + exercise $(\boldsymbol{\Delta})$, control + caffeine rats $(\square)$, diabetic rats + caffeine $(\diamond)$, control rats + exercise + caffeine $(\boldsymbol{\square})$ and diabetic rats + exercise + caffeine $(\bullet)$. The data are presented in mean \pm SEM, $n=6$, different letters $(a, b, c)=P<0.05$ (Tukey after one-way MANOVA).

groups had higher values compared to control animals $(233 \%, F(7.41)=6.626, P<0.001)$, but without significant difference for Diabetes+Exercise and Diabetes+Exercise+Caffeine groups $(33 \%, F(7.41)=$ 6.626, $\mathrm{P}=0.782$ ).

Figure 5 represents the glycogen values observed in the hepatic and muscular tissues of the animals after training and / or treatment with caffeine. No significant differences were observed for both hepatic glycogen $(F(7.41)=1.407)$ and muscle glycogen $(F(7.41)=$ 1160).

Figure 6 represents the ratio of homeostasis and insulin resistance (HOMA-IR) and the insulin resistance index in the different groups after training and/or 

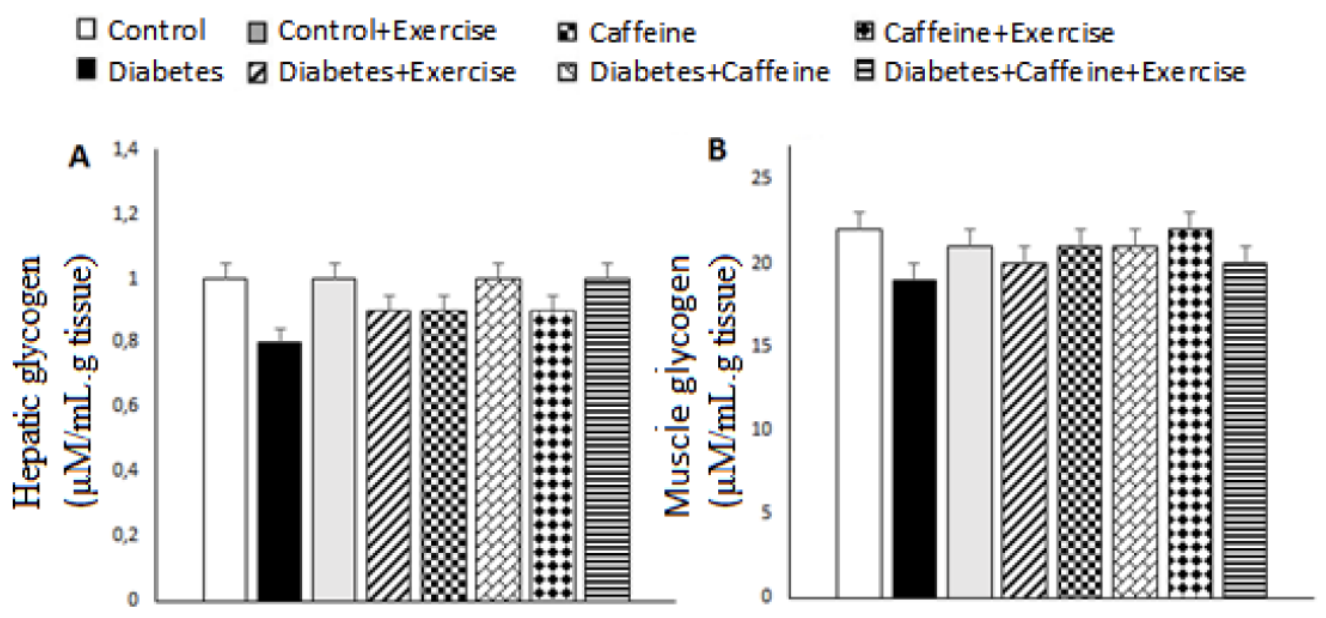

Figure 5: Concentration of $(\mathbf{A})$ muscle hepatic and $(\mathbf{B})$ muscle glycogen after training and / or treatment with caffeine. Data are presented in mean $\pm \mathrm{SEM}, \mathrm{n}=6,{ }^{*}=\mathrm{P}<0.05$ when compared to the other groups (Tukey after MANOVA).

treatment with caffeine. The values related to HOMA-IR increased for the groups Diabetes and Diabetes + Caffeine after training and/or treatment $(78 \% ; \mathrm{F}(7.41)=$ 3.927; $p=0.016$ ) compared to Control, Exercise and Diabetes + Exercise groups. The values for the group Caffeine, Exercise + Caffeine and Diabetes+Exercise+ Caffeine had a significant increase $(50 \%, F(7.41)=$ 3.927, $p=0.006$ ) compared to the Diabetes and Diabetes + Caffeine groups, and a significant increase compared to Control, Exercise and Diabetes + Exercise $(120 \%, F(7.41)=3.927, p=0.006)$.

In relation to the insulin resistance index, there were increases for the groups Diabetes, Exercise + Caffeine, and Diabetes + Exercise + Caffeine $(50 \%, F(7.41)=$ 4.029, $p=0.014$ ) after training and / or treatment compared to the Control, Exercise, Diabetes + Exercise and Diabetes + Caffeine groups. In addition, the caffeine group had a significant increase compared to the groups Diabetes, Exercise + Caffeine, and Diabetes + Exercise + Caffeine $(55 \%, F(7.41)=4.029$, $\mathrm{p}=0.005)$ Diabetes + Exercise and Diabetes + Caffeine $(77 \%, F(7.41)=4.029, p=0.005)$.

\section{DISCUSSION}

In the long term, studies have shown that caffeine did not alter [12] or even increased glucose tolerance [9], insulin sensitivity [13] and control [13], as well as reduced concentrations of catecholamines (epinephrine and corticosterone) [14].

As for the unmodified levels of glycogen, both hepatic and muscular, they may have been influenced by the effect of physical exercise 48 hours before the sacrifice of the animals, which tends to reduce or deplete the glycogen stores in the tissue, due to their energy needs.
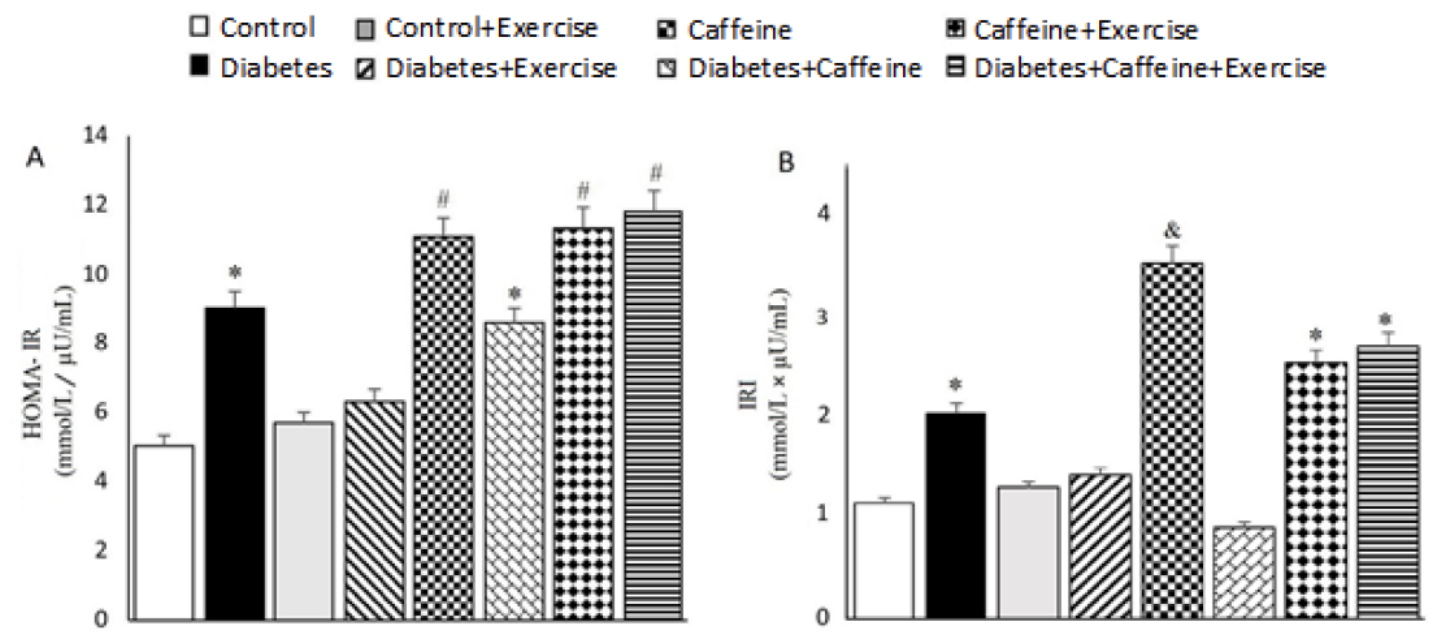

Figure 6: Reason for insulin resistance (HOMA-IR) (A) and Insulin Resistance Index (B) after training and / or treatment with caffeine. The data are presented in mean $\pm \mathrm{SEM}, \mathrm{n}=6$, ${ }^{*}$ or $\#=\mathrm{P}<0.05$ when compared to the other groups, $\&=P<0.05$ when compared to: Control, Control + Exercise, Diabetes + Exercise, Caffeine (Tukey after MANOVA). 
The DM demarcates metabolic changes on the consumption of energy substrates that are used for the maintenance of energy and cellular life. Caffeine intake resulted in changes in diabetic rats, improving glucose tolerance after OGTT and increasing hepatic and muscle glycogen, but maintained postprandial plasma glucose values increased compared to diabetic control animals. These effects bring metabolic responses on energetic substrates, such as increased fatty acid mobilization, increased glycerol, and increased uptake and glucose tolerance, as seen in the OGTT and in the hepatic and muscular glycogen concentration.

Studies showing the action of caffeine on glycemic and fatty acid behavior in relation to changes in catecholamines, insulin sensitivity and glucose tolerance in humans, evaluating the mechanisms and events in homeostasis of energy metabolism, may be a way of coping with conditions of glucose intolerance, insulin resistance and diabetes mellitus in the clinical area.

Training and treatment with caffeine altered metabolic values after 4 weeks of intervention. The values of weekly, postprandial, and OGTT fasting glucose demonstrate that exercise improves plasma glucose control by increasing glucose tolerance to be captured by skeletal muscle, and when combined with caffeine, the results are similar for glucose tolerance.

Caffeine training and treatment reversed high albumin values in diabetic animals, demonstrating that a possible dehydration caused by the disease was controlled and could be related to a better energy efficiency resulting from a higher amount of substrate stored after caffeine consumption. greater use by physical exercise.

In this context, caffeine showed a significant decrease in glycemia, acting on glycemic metabolism. Different doses compared to different intensities of exercise can alter the glycemia metabolism. Thus, the need for more studies evaluating low doses of caffeine against moderate-intensity exercises, within its varied types (eg swimming, walking, weathering), is reinforced.

Still, the work with different doses should be performed, because the dose-response curve may be different, as well as smaller values can be significant, achieving satisfactory values in glycemic control, and may be interesting in the treatment of diabetes mellitus.

\section{CONCLUSION}

This work showed which caffeine and training with aerobic exercise in healthy and diabetic animals' is an important animal glycemic control tool because it can improve systems essential for metabolic balance as skeletal muscle, which plays an important role both in motion, increasing the physical ability of the body to resist situations seeking to adapt the tissues to better function.

\section{ACKNOWLEDGEMENTS}

The authors are thankful to CAPES (Brazil) and Fundação Araucaria of Paraná (Brazil) for the financial support to this study.

\section{DECLARATION OF INTEREST}

There are no issues to disclose. There is no potential conflict of interest.

\section{REFERENCES}

[1] Nolan CJ, Damm P, Prentki M. Type 2 diabetes across generations: from pathophysiology to prevention and management. Lancet 2011; 378(9786): 169-81. https://doi.org/10.1016/S0140-6736(11)60614-4

[2] Colberg SR, Sigal RJ, Fernhall B, Regensteiner JG, Blissmer BJ, Rubin RR. Exercise and type 2 diabetes: the American College of Sports Medicine and the American Diabetes Association: joint position statement. Diabetes Care 2010; 33(12): 147-67 https://doi.org/10.2337/dc10-9990

[3] Sato E, Suzukamo Y, Miyashita M, Kazuma K. Development of a Diabetes Diet-Related Quality-of-Life Scale. Diabetes Care 2004; 27(6): 1271-1275 https://doi.org/10.2337/diacare.27.6.1271

[4] Hu FB, Manson JE, Stampfer MJ, Colditz G, Liu S, Solomon CG. Diet, Lifestyle, and the Risk of Type 2 Diabetes Mellitus in Women. N Eng J Med 2001; 345(11): 790-7. https://doi.org/10.1056/NEJMoa010492

[5] Horimatsu T, Fujii K, Fukunaga M, Nishimura M. Impact of Acute Hyperglycemia on Microvascular Damage and Longterm Clinical Outcomes in Patients With ST-elevation Myocardial Infarction. Circulation 2015; 132(15416): 2015.

[6] Howarth FC, Al-Ali S, Al-Sheryani S, Al-Dhaheri H, Al-Junaibi $\mathrm{S} S$, Almugaddum FA, et al. Effects of voluntary exercise on heart function in streptozotocin (STZ) - induced diabetic rat. Int J Diabetes Metabolism 2007; 15: 32-37.

[7] American Diabetes Association. Physical Activity/Exercise and Diabetes Mellitus. Diabetes Care 2006; 29(1): 1433-38.

[8] Graham TE, Battram DS, Dela F, El-Sohemy A, Thong FS. Does caffeine alter muscle carbohydrate and fat metabolism during exercise? Appl Physiol Nutr Metab 2008; 33(6): 131188

https://doi.org/10.1139/H08-129

[9] Guarino MP, Ribeiro MJ, Sacramento JF, Conde SV. Chronic caffeine intake reverses age-induced insulin resistance in the rat: effect on skeletal muscle Glut4 transporters and AMPK activity. Age (Dordr) 2013; 35(5): 755-65. https://doi.org/10.1007/s11357-012-9475-x

[10] Gobatto CA, Mello MAR, Sibuya CY, Azevedo JRM, Santos LA, Kokubun E. Maximal lactate steady state in rats 
submitted to swimming exercise. Comp Biochem Physiol Part A 2001; 130: 21-27.

$$
\text { https://doi.org/10.1016/S1095-6433(01)00362-2 }
$$

[11] Scariot PP, Manchado-Gobatto FB, Torsoni AS, Dos Reis IM, Beck WR and Gobatto CA. Continuous Aerobic Training in Individualized Intensity Avoids Spontaneous Physical Activity Decline and Improves MCT1 Expression in Oxidative Muscle of Swimming Rats. Front Physiol 2016; 7: 132. https://doi.org/10.3389/fphys.2016.00132

[12] Wedick NM, Brennan AM, Sun Q, Hu FB, Mantzoros CS, Van Dam RM. Effects of caffeinated and decaffeinated coffee on biological risk factors for type 2 diabetes: a randomized controlled trial. Nutr J 2011; 13(10): 93. https://doi.org/10.1186/1475-2891-10-93
[13] Yamauchi R, Kobayashi M, Matsuda Y, Ojika M, Shigeoka S, Yamamoto Y, Tou Y, Inoue T, Katagiri T, Murai A, Horio F. Coffee and caffeine ameliorate hyperglycemia, fatty liver, and inflammatory adipocytokine expression in spontaneously diabetic KK-Ay mice. J Agric Food Chem 2010; 58(9): 5597603.

https://doi.org/10.1021/jf904062c

[14] Conde SV, Silva TN, Gonzalez C, Carmo MM, Monteiro EC, Guarino MP. Chronic caffeine intake decreases circulating catecholamines and prevents diet-induced insulin resistance and hypertension in rats. Br J Nutr 2012; 107: 86-95. https://doi.org/10.1017/S0007114511002406 